\title{
River bed classification using multi-beam echo-sounder backscatter data
}

\section{Niels KINNEGING}

Rijkswaterstaat Centre for Water Management

Mirjam SNELLEN

Delft University of Techonology

Dimitrios ELEFTHERAKIS

Delft University of Technology

Dick SIMONS

Delft University of Technology

Erik MOSSELMAN

Deltares \& Delft University of Technology

\section{Arjan SIEBEN}

Rijkswaterstaat Centre for Water Management

Topic: $\mathrm{K}$ Hydrography in the Benelux

\section{INTRODUCTION}

The Netherlands form the delta for some of the major river systems of Europe, comprising the Rhine, the Meuse, the Scheldt and the Eems. These rivers are valuable parts of national and international ecological networks and are of high economic importance. A minimum depth should be guaranteed to keep the rivers navigable. This depth depends not only on water discharge but also on river bed topography that changes dynamically in response to discharge fluctuations.

Rijkswaterstaat is the Dutch governmental organization that is responsible to maintain the main river systems for both shipping, flood conveyance and ecological purposes. To keep the rivers navigable daily dredging activities are carried out. Furthermore the discharge capacity of the rivers is enlarged and the ecological quality is improved by widening the river and making secondary channels.

The river topography and its dynamics are affected by spatial variations in bed sediment composition, thus making knowledge of the spatial sediment distribution highly important. It proved to be sufficient to detect a number of classes to produce classification maps of the bottom.

An attractive system to be used for obtaining information on both the river bed bathymetry and sediment composition is the multi-beam echo-sounder (MBES). This sonar emits short pulses of sound towards the river bed to determine the depth and the backscatter strength for a large number of closely-spaced beams. The MBES provides high spatial coverage of an area at moderate costs and within short time. The backscatter strengths are known to be indicative for the sediment types, and consequently have potential with regard to sediment classification. Consequently, the MBES system appears as a good alternative to the conventional, expensive and time-consuming, approach of mapping the river bed composition by taking a large number of physical sediment samples.

In the present paper, the results of a novel and fairly simple sediment classification method are presented. The method that developed in the Acoustic Remote Sensing Group of Delft University of technology is briefly described in the following section. 


\section{BAYESIAN CLASSIFICATION METHOD (BCM)}

The BCM - developed in [1] for deep waters and extended in [2] for shallow waters ( $~ 4 \mathrm{~m}$ depth) employs the backscatter strengths per angle, i.e., separately from other angles. The method is based on the assumption that the beam backscatter values are an average value of the sample amplitude values corresponding to all scatter pixels that fall within the beam footprint. Therefore, according to the central limit theorem, the averaged backscatter value for a single sediment type follows a Gaussian distribution for a sufficiently large number of scatter pixels.

The method fits a number of Gaussian Probability Density Functions (PDFs) to the histogram of the backscatter data at a given incident angle, i.e.,

$$
B S \sim f_{B S}(B S)=\sum_{i=1}^{r} c_{i} N\left(B S ; \mu_{i}, \sigma_{i}^{2}\right)
$$

where $\mu_{i}$ and $\sigma_{i}^{2}$ are the mean and variance of the th PDF, respectively, and $c_{i}$ is the contribution of the individual Gaussian functions to the total PDF. $f_{B S}$ is the fitted histogram. The optimum number of PDFs is found by consecutively increasing the number of PDFs until the chi-square distributed teststatistic of the residuals becomes close to one. The number of Gaussians then represents the maximum number of classes that can be discriminated based upon the backscatter values, and the borders of the classes are the intersections of each Gaussian with its neighbour.

The flowchart of the processing steps is presented in Figure 1. First the backscatter values are averaged over small surface patches, consisting of a small number of beams in the across-track direction and a few pings in the along-track direction. Then the backscatter data at a few outer angles are processed in order to estimate the mean backscatter strength, the variance and its coefficient per class. These parameters are used as guidance for the statistical processing of all other angles.

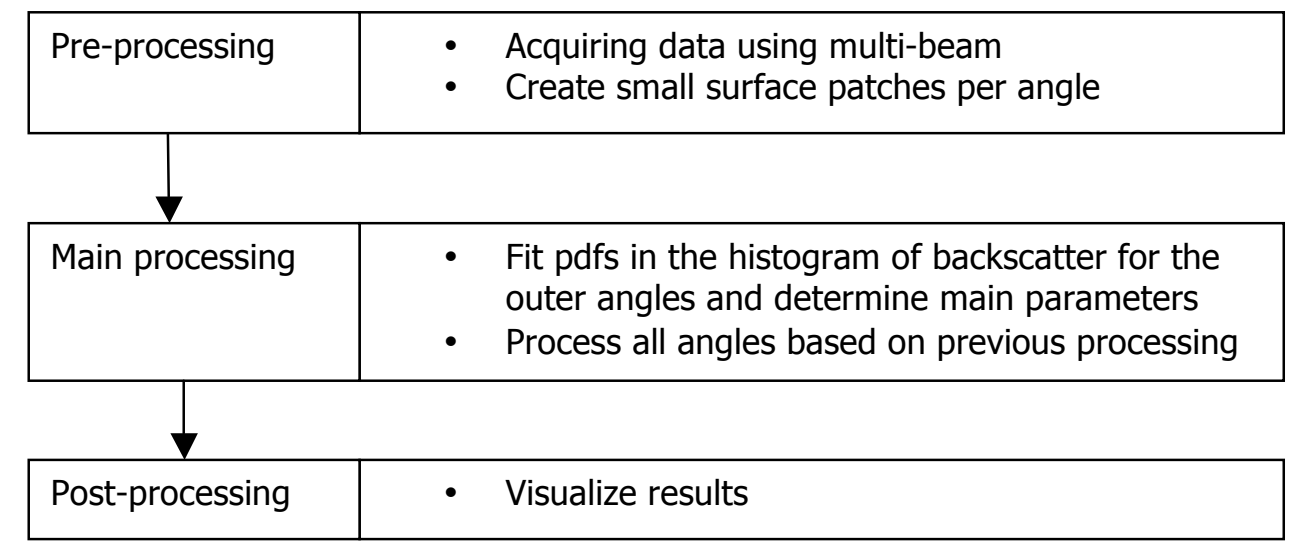

Figure 1: Flowchart of the BCM steps.

\section{RESULTS}

The method has been tested on different parts of the Dutch rivers with shallow water and river bed types that range from silt, clay and peat to sand, gravel and pebbles. Table I provides an overview of the specifics of the areas considered.

In addition to the MBES measurements also grabs were taken. Figure 2 illustrates the mean grain sizes as derived from the grabs for all areas. 
Table I

\begin{tabular}{|l|l|l|}
\hline Area & Area specifics & Measurement specifics \\
\hline 1. Sint Andries & Fixed layer present; Water depth $\sim 5 \mathrm{~m}$ & $\begin{array}{l}\text { Surveyed in 2007. A small part of it } \\
\text { Was surveyed again in 2008. }\end{array}$ \\
\hline $\begin{array}{l}\text { 2. Waal-close } \\
\text { to Nijmegen }\end{array}$ & Fixed layer present; Water depth $\sim 6 \mathrm{~m}$ & Surveyed in 2008 \\
\hline 3. Upper Rhine & Water depths $\sim 4.5-\sim 2.5 \mathrm{~m}$ & Surveyed in 2008 \\
\hline 4. Dordtse Kil & $\begin{array}{l}\text { Part of the river has irregular surface } \\
\text { due to the presence of deep holes. } \\
\text { Water depth } \sim 11 \mathrm{~m}\end{array}$ & $\begin{array}{l}\text { Surveyed in 2009. Additional } \\
\text { measurements with device that is } \\
\text { measuring the radioactivity of } \\
\text { sediments. }\end{array}$ \\
\hline 5. Meuse & $\begin{array}{l}\text { Very coarse riverbed } \\
\text { Water depth } \sim 3 \mathrm{~m}\end{array}$ & Surveyed in 2010 \\
\hline
\end{tabular}

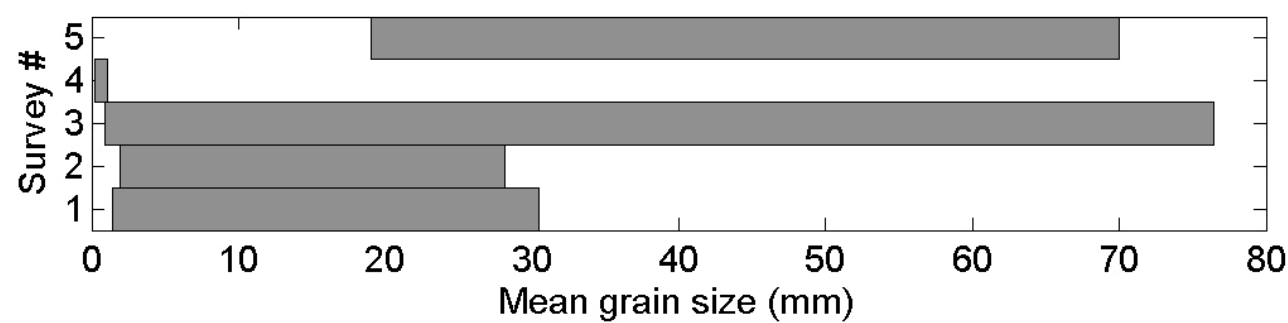

Figure 2: Mean grain size values encountered in the different areas.

The method was found to be able to discern between different sediments for all areas. Figure 3 shows two examples of applying the method to Dutch rivers. Figure 3 left presents a part of the river Waal close to Sint Andries. The data at outer angles was collected and three PDFs (thus 3 classes) fit their histogram (Figure 3 top-left). The sediment distribution map of Sint Andries is presented in Figure 3 bottom left. Mean grain size values were assigned to each class after comparing the classification results to a number of physical samples taken in the area (small frames). The fixed layer was identified when combining the backscatter with the depth residuals (see Ref. [3]).The results of another river (Dordtse Kil) that has a larger variation of sediments is shown in Figure 3 right. In this case, five PDFs were needed to sufficiently fit the histogram of the backscatter (Figure 3 top right) and the resulted sediment classification map is presented in Figure 3 bottom right.

The availability of bathymetric data in combination with the classification allows for a detailed assessment and interpretation of the sediments in an area. An example for Sint Andries river is presented in Figure 4, where the bathymetry is shown in 3D (Figure 4 left) and then the resulted classes are projected on top of the bathymetry map (Figure 4 right). 

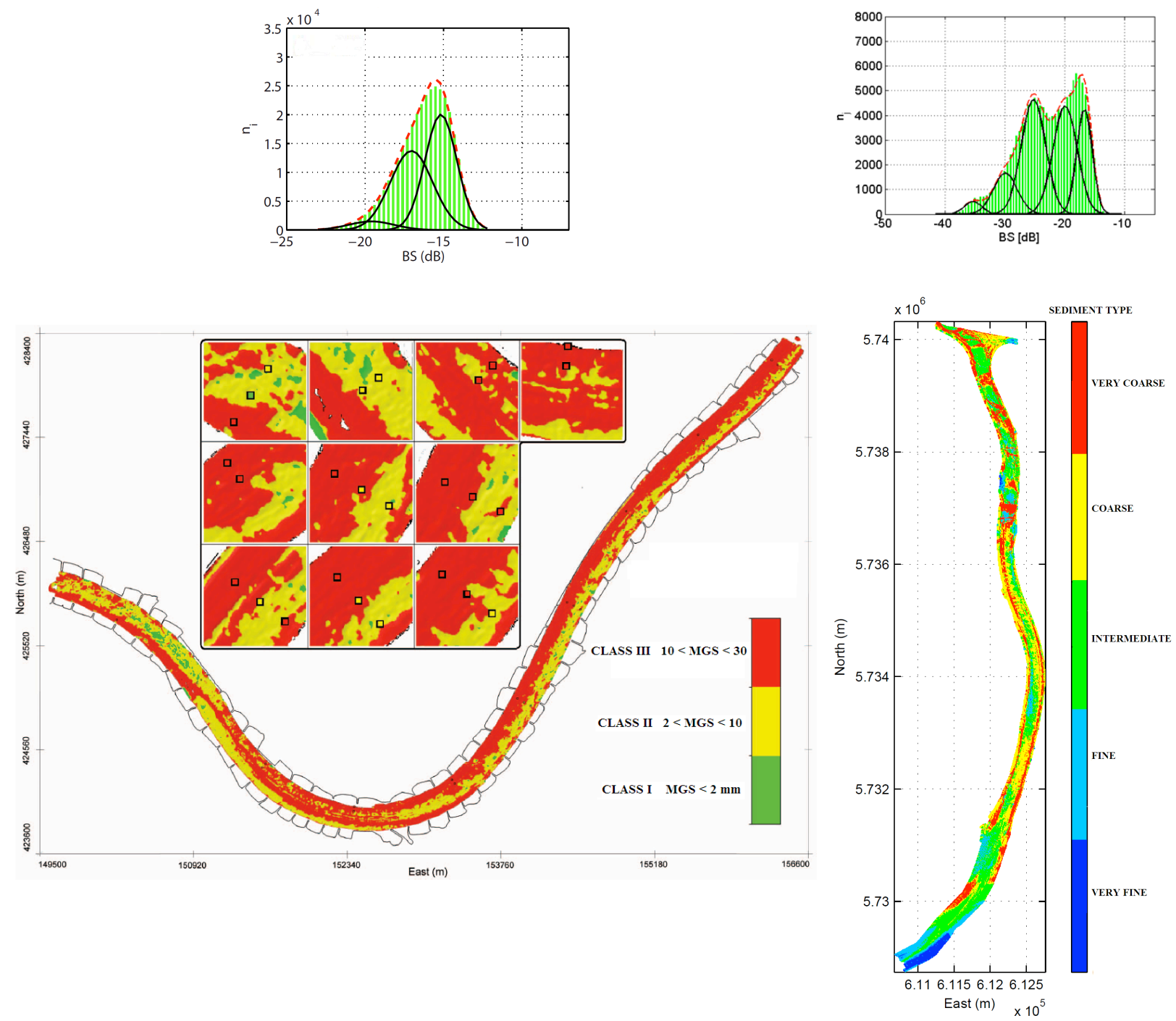

Figure 3: Pdfs fitted in the backscatter strength histogram of outer angles (top) and sediment classification maps (bottom) for Sint Andries (left) and Dordtse Kil (right). 

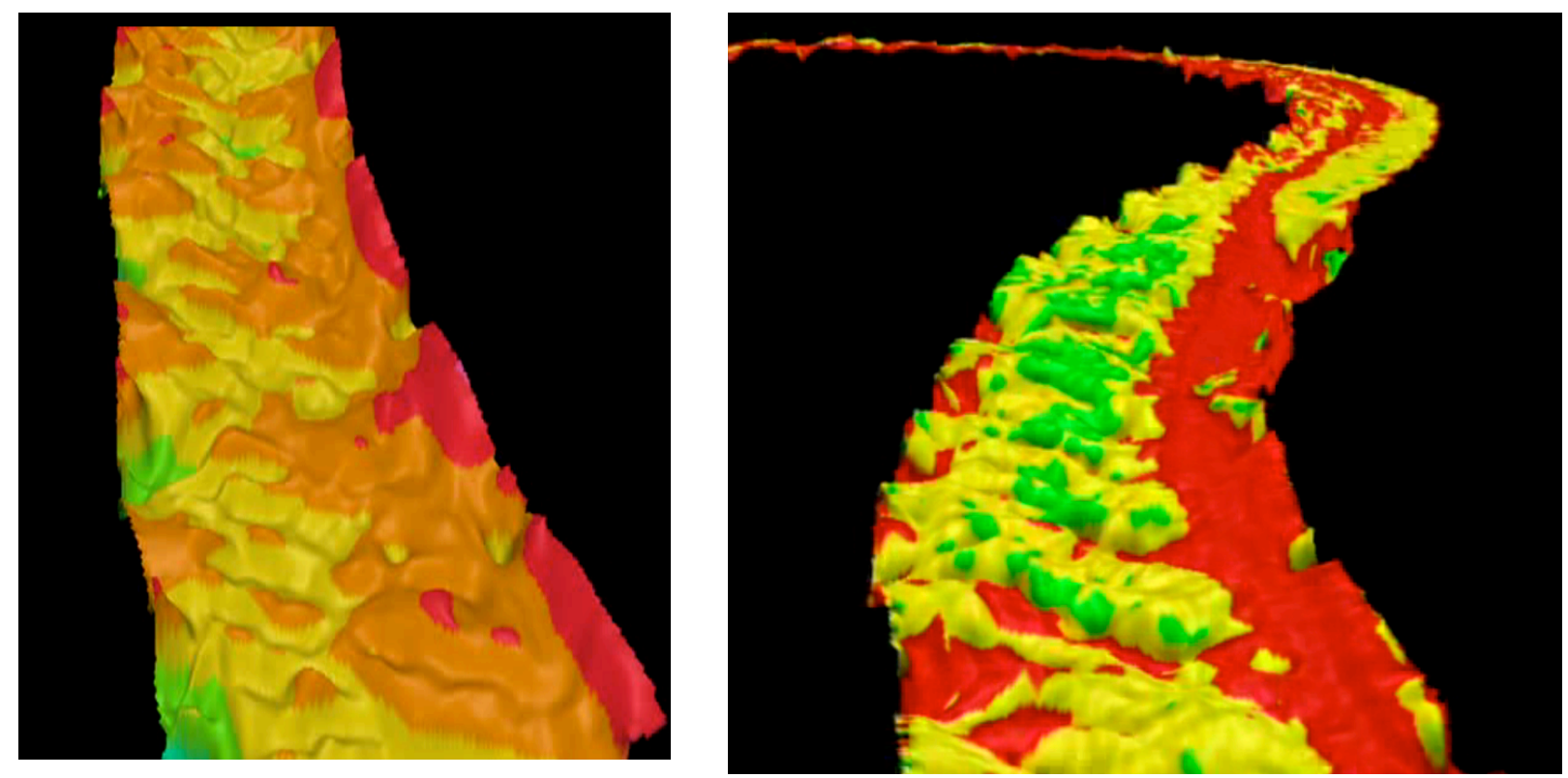

Figure 4: 3D bathymetry map (left) and sediment classes projected on top of the bathymetry map (right) for Sint Andries.

\section{CONCLUSIONS}

In this paper we presented a method for classication of the river sediments. Using the backscatter information of a multibeam echosounder system the method was found to be able to discern between different sediments for all areas over a large range of mean grain sizes. The main advantages of using the BCM for sediment classification include:

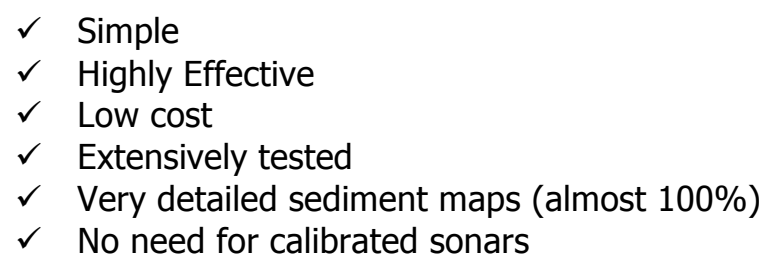

At this moment the method has been applied using data of the EM3002 system However, since also other MBES systems (can) provide the backscatter strengths, the method can also be applied to the data acquired with these systems. For a routine implementation of the method in the work of Rijkswaterstaat it should be incorporated in the standard data acquisition and data processing packages.

Further improvement can be expected if the MBES systems would not only be calibrated for arrival times, but also for the transmitted and received amplitude information. If that information would be available the amount of ground truthing can be reduced considerably.

An alternative line of research and development is that the MBES systems are tested on known sediment beds in a laboratory flume. This is currently discussed within a co-operation between the faculties of Aerospace Engineering and Civil Engineering and Geosciences at Delft University of Technology. 


\section{REFERENCES}

1. D.G. Simons, and M. Snellen. "A Bayesian approach to seafloor classification using multi-beam echo-sounder backscatter data", Appl. Acoust. 70, 1258-1268 (2009).

2. A.R. Amiri-Simkooei, M. Snellen, and D.G. Simons, "Riverbed sediment classification using multibeam echo-sounder backscatter data", J. Acoust. Soc. Am. 126, 1724-1738 (2009).

3. D. Eleftherakis, A.R. Amiri-Simkooei, M. Snellen, and D.G. Simons, "Improving riverbed sediment classification using backscatter and depth residual features of multi-beam echo-sounder systems", J. Acoust. Soc. Am. 131(5), 3710-3725, (2012).

4. D. Eleftherakis, E. Mosselman, A.R. Amiri-Simkooei, S. Giri, M. Snellen, and D.G. Simons. "Identifying changes in river bed morphology and bed sediment composition using multi-beam echosounder measurements", In: Proc. of the 10th European conference on Underwater Acoustics, Istanbul, Turkey, 1365-1373 (2010).

5. M. Snellen, D. Eleftherakis, A.R. Amiri-Simkooei, R. Koomans, and D. Simons, "An inter-comparison of sediment classification methods based on multi-beam echo-sounder backscatter data and sediment natural radio-activity", submitted to JASA (under review).

\section{BIOGRAPHIES}

Niels KINNEGING got his Ph.D. in Applied Physics from the Delft University of Technology. Presently is is responsible for the co-ordination of all hydrographic activities at Rijkswaterstaat, the Dutch governmental organisation for water management.

Mirjam SNELLEN SNELLEN got het Ph.D. from the University of Amsterdam. Presently she is assistant professor in the field of Acoustic Remote Sensing at the Delft University of Technolgy

Dimitrios ELEFTHERAKIS is currently a PhD student in underwater acoustic remote sensing at the Delft University of Technology (TU Delft). He is mechanical engineer with a Master degree in offshore and ocean technology.

Dick SIMONS is a physicist specialized in acoustics, signal processing and remote sensing. He received his PhD from the University of Leiden in 1988. In 2004 he was appointed professor in Acoustic Remote Sensing at the Delft University of Technology. Within his chair various sediment classification methods are being developed for imaging sonar systems, including the multibeam echosounder.

Erik MOSSELMAN is a river morphologist at Deltares and Delft University of Technology. He worked on numerous rivers in Europe, Asia and South America. One of his research interests regards the interaction between sand and gravel on the river bed.

Arjan SIEBEN is a river engineer at Rijkswaterstaat, engaged with river projects on flood level safety, fairway improvement and maintenance.

\section{CONTACT DETAILS}

Niels KINNEGING

Rijkswaterstaat Centre for Water Management

P.O. Box 17

$\mathrm{NL}-8200$ AA Lelystad

THE NETHERLANDS

Tel.: +31653215242

Email: niels.kinneging@rws.nl

Web site: www.rijkswaterstaat.nl

LinkedIn account: http://nl.linkedin.com/pub/niels-kinneging/5/2aa/aab 